\title{
ASSIS, João Marcus Figueiredo; RODRIGUES, Denise dos Santos (Org.). Cidadania, movimentos sociais e religião: abordagens contemporâneas. Rio de Janeiro: EdUERJ, 2013. $252 \mathrm{p}$.
}

Jair Souza Leal *

Esta obra é uma coletânea de doze artigos reunidos "em torno do eixo temático Religião e Movimentos Sociais". Contém um artigo de abertura e dois grandes blocos, o primeiro com seis artigos, o segundo com cinco comunicações. Os artigos foram escritos por doutores e mestres do campo das ciências sociais de variadas instituições, participantes do simpósio Cidadania, Movimentos Sociais e Religião, no III Congresso Internacional do Núcleo de Estudos das Américas: Processos Civilizatórios e Crises do Capitalismo Contemporâneo, realizado em agosto de 2012, na UERJ, e textos de autores convidados. Os artigos são "resultados de pesquisas empíricas, levantamentos bibliográficos e registros de acontecimentos relevantes", que tornam a obra relevante para a compreensão de diversos problemas dos tempos atuais, "práticas sociais e religião", além de contribuir para a "construção da cidadania e dos direitos humanos". Quanto aos organizadores, Assis é professor adjunto do Centro de Ciências Humanas e Sociais da UNIRIO, Rodrigues é doutora em Ciências Sociais pela UERJ - autores cuja extensa produção acadêmica avaliza a qualidade do debate oferecido pela publicação. 
O artigo de abertura, A Igreja e a ditadura militar, de autoria do sociólogo Ivo Lesbaupin, doutor em Sociologia pela Universidade de Toulouse-Le-Mirail, “apresenta o posicionamento da Igreja Católica durante a ditadura militar”, em especial os acontecimentos da década de 1960. Ele apresenta o período antecedente à ditadura, quando a igreja tinha pouco interesse e participação na questão social e ajudava a manter a estrutura social vigente. Destaca, em seguida, o início das efervescências no campo, no movimento operário e sindical, na educação, o impulso da vitória da revolução Cubana, a atuação dos padres operários franceses e as decisões do Concílio Vaticano II, que contribuem para o surgimento da CNBB e da Teologia da Libertação e passam a envolver bispos e leigos nas ações políticas. $\mathrm{Na}$ sua exposição, com o golpe, a Igreja no primeiro momento convive pacificamente, em clima oficial de aprovação. Entretanto, o endurecimento do regime faz crescer uma ala da Igreja com posições mais críticas. Por fim, a Igreja se posiciona "em defesa dos direitos humanos, dos pobres, dos indígenas, dos trabalhadores, dos posseiros, dos oprimidos". Surgem as Comunidades Eclesiais de Base e a Campanha da Fraternidade. No contraponto, o autor indica como a intervenção do Vaticano, no pontificado de João Paulo II, cria dificuldades para as lideranças que lutavam contra o regime, culminando na condenação da Teologia da Libertação. Termina o autor analisando que, findo o regime, a Igreja se torna novamente tradicional, sem participação social.

O segundo artigo, que inicia a Parte I, tem como título: Religiosidade jovem: reflexo da crise do pertencimento institucional nas fileiras do alistamento militar. É da autoria de Denise dos Santos Rodrigues, doutora em Ciências Sociais pela UERJ. Através de pesquisa feita com jovens da Região Metropolitana do Rio de Janeiro, entre 18 e 20 anos, quando do alistamento militar no ano de 2009, a autora analisa a questão da religiosidade. Seus apontamentos indicam tendências variadas, como queda de católicos, crescimento de evangélicos e dos sem-religião. Fala dos traços de destradicionalização, das tendências secularizantes, da crise de pertencimento, do papel da família na formação religiosa, da religiosidade 
desvinculada da instituição. Conclui afirmando que o resultado de sua pesquisa aponta as tendências “que se consolidarão no futuro'. Grosso modo, a pesquisa da autora trouxe à discussão muitos dados levantados pelos últimos censos do IBGE.

Favela e pacificação. Religião e Estado no ordenamento do espaço social, é o próximo artigo, da autoria de João Marcus Figueiredo Assis, um dos organizadores do livro. Ele analisa a vida dos moradores de uma favela carioca, local onde residiu para experiência prática da pesquisa. Assim, faz importantes apontamentos sobre a questão religiosa e o desempenho do Estado neste importante e fragmentado espaço social. Foca as incorretas intervenções da Polícia Pacificadora ocorridas na época da sua pesquisa. Destaca os modos como a desigualdade de renda e a dificuldade de moradia e de acesso aos serviços públicos, naqueles espaços, denunciam o jogo capitalista e o processo industrial, além da má distribuição de renda no país. Por fim, revela como, influenciados pela Teologia da Libertação, religiosos se doam em ações humanitárias visando minimizar o caos social da região pesquisada.

O próximo artigo tem por título Ideologia político-religiosa $x$ políticopragmática: o caso dos movimentos sociais no Brasil. É de autoria do professor Nadir Lara Júnior, doutor em Psicologia Social pela PUC-SP. Em sua pesquisa ele dedica-se a fazer uma "análise psicossocial da influência dos elementos religiosos na constituição da ideologia política” do MST, do Movimento de Moradia de São Paulo e do Movimento de Mulheres Camponesas de Passo Fundo (RS), que segundo ele "trazem em sua gênese a influência do cristianismo e do marxismo". Ele contextualiza os movimentos, apresenta seus pontos comuns e expõe dados que demonstram que certos acontecimentos históricos importantes no Brasil mudaram a ideologia político-religiosa daqueles movimentos, que hoje têm se alinhado ao discurso capitalista e que antes combatiam.

Valores religiosos na organização da luta pela terra: estudo sobre os assentamentos de Sumaré-SP é o título do próximo texto, da autoria de Vitor 
Barletta Machado, doutor em Sociologia pela UNICAMP. Seu texto é resultado das pesquisas realizadas nos assentamentos rurais da cidade paulista de Sumaré, e analisa o papel da fé religiosa na formação e organização dos mesmos. Ele apresenta dados históricos sobre a gênese e desenvolvimento destes assentamentos, que têm início em 1982, anos finais da ditadura militar, e que os mesmos são importantes como polo de atração populacional em tempos de crise econômica. Ele discute como a fé religiosa teve papel fundamental para o sucesso inicial do movimento, e como, hoje, é apenas uma vaga lembrança para as novas gerações.

O próximo texto, Uma análise do pluralismo e o diálogo inter-religioso como instrumento das lutas sociais em comunidades de Petrópolis é da autoria de Luci Faria Pinheiro, doutora em Antropologia e Sociologia Política pela Université Paris 8, na França. Seu texto parte da visão do ecumenismo religioso como sendo um importante movimento de luta e defesa dos interesses sociais. Ela abrange elementos conceituais e históricos do ecumenismo e esbarra no desafio do pluralismo e do diálogo inter-religioso. Faz uma importante análise do pluralismo e do papel do diálogo inter-religioso mas, a meu ver, não consegue fazer o link com a ideia proposta de vincular sua análise às comunidades de Petrópolis.

Indivíduo solidário e colaborador: notas sobre a construção do conceito de cidadania em tempos neoliberais é o próximo artigo, da autoria de Gisele dos Reis Cruz, doutora em Sociologia pelo Instituto Universitário de Pesquisa do Rio de Janeiro, e é o último artigo da primeira parte. A autora trabalha no texto o conceito de cidadania no contexto histórico brasileiro, entre o processo de democratização dos anos 80 aos dias atuais, os quais considera como "neoliberal". Na sua análise ela avalia o papel das ONGs como sendo resultado do modelo neoliberal, apontando vantagens e desvantagens destas instituições na construção da cidadania. Ela defende modelos diversos os quais considera emancipatórios da cidadania, e não mantenedores como são os modelos atuais, referindo-se às entidades de assistência social. No seu artigo, em nenhum momento transparece 
algum elemento religioso.

Iniciando a parte dois, composta dos cinco últimos artigos, o primeiro artigo é intitulado: Militância de jovem: Pastoral da Juventude e a ideologia petista na diocese de Nova Iguaçu. Da autoria de Ronald Apolinário de Lira, Doutorando em Ciências Sociais na UERJ. Em seu artigo o autor tem por foco a diocese de Nova Iguaçu (RJ), influenciada pela Teologia da Libertação, e como a juventude desta diocese foi importante ator social, assessorada por bispos, padres e leigos, e que culminou do nascimento do PT na região à eleição de políticos de expressão nacional. Ele apresenta o pano de fundo histórico da diocese, as lutas enfrentadas, a influência da Teologia da Libertação na mesma, o papel da Pastoral da Juventude. Por fim, apresenta como a religião deu sentido à vida e à luta das pessoas, e que culminou em diversas mudanças no país e em influências que ainda hoje se fazem sentir no cenário nacional.

Espionagem, inculpações e repressão na Baixada Fluminense: a Igreja Católica e a rede de subversivos é o próximo artigo, da autoria de Abner Francisco Sótenos, mestre em História Social pela UFRJ. Seu artigo tem por finalidade analisar o período da abertura política (1974-1985), a partir de documentos dos próprios órgãos de repressão. Seu foco está especialmente em investigar a atuação do bispo Dom Adriano Hypólito, na diocese de Nova Iguaçu, o qual se posicionou contra o regime militar e se tornou alvo da repressão. O autor faz uma breve exposição histórica de como a Igreja Católica durante o regime oscilou entre apoio e crítica ao regime; e, nesse último caso, em especial na diocese de Nova Iguaçu, enfrentou forte oposição do regime, com duras críticas, sequestro do bispo, acusações de comunismo e até de ser ameaça à segurança nacional.

O próximo artigo tem por título $A$ secularização do Brasil na Primeira República e a criminalização do espiritismo, é da autoria de Adriana Gomes, mestre em História Política da UERJ. Em seu texto a autora percorre uma questão histórica, de como legalmente o Brasil caminhou da Hegemonia para o pluralismo, 
ou laicidade. Aborda como protestantes e evangélicos, a longo prazo, foram os primeiros a desfrutar a liberdade religiosa, enquanto o espiritismo enfrentava a intolerância dos órgãos e agentes estatais, que o criminalizava, mantinha-o na ilegalidade. Ela aborda o duro caminho percorrido pelo espiritismo para legitimarse no Brasil laico.

Subjetividades de mulheres negras cearenses: um olhar sobre suas histórias e memórias, da autoria de Maria Saraiva da Silva, mestra em educação brasileira pela Faculdade de Educação da Universidade Federal do Ceará. Em seu artigo a autora afirma que "a oralidade baseada em memórias é uma fonte de investigação”, fato que permite reconstruir a história. Com tal pressuposto, tenta reconstruir a história da população negra feminina do Ceará. Destaca todo o preconceito social existente em torno de mulheres negras e velhas e afirma que elas são histórias vivas, ponte entre o presente e passado. Afirma ainda que tais mulheres podem trazer à tona o conhecimento de "lutas e conquistas nos diversos contextos sociais”. A proposta do tema apresenta-se deveras instigante. Entretanto, a expectativa criada no leitor não chega a ser satisfeita. Pareceu-me que, na preocupação por defender a validade metodológica da história oral, a autora acabou por deixar em plano secundário o prometido objeto de sua pesquisa.

A reestruturação social a partir de uma manifestação religiosa no interior paulista da autoria de Mariana Vieira, graduada em Ciências Sociais, é o último artigo do livro. Nele a autora visa entender "o sentido da religião na sociedade rural paulista" e como a religiosidade legitima ou justifica estruturas tradicionais. Ela apresenta sua metodologia de pesquisa e em seguida mostra o que desencadeou um importante fenômeno religioso e social na região, o "menino da tábua”, que se tornou objeto sagrado. Assim, por meio da análise deste fato ela faz considerações em torno da religiosidade, apontando que esta pode contribuir para a formação social e até para exploração política. 
Mesmo sendo um conjunto de artigos, o livro apresenta recortes de períodos da história brasileira, de lugares, pessoas e movimentos, os quais, a partir do viés sociológico, contribui para esclarecer como a religião, ao lado dos movimentos sociais, pode formar a memória e a história do país, seja mantendo a estrutura existente, seja transformando-a. Assim, no todo da publicação, os autores alcançam o objetivo proposto em seus textos e fazem deste livro um importante referencial para os estudos que abordam as relações entre religião, cidadania e movimentos sociais na contemporaneidade. 